\title{
KNACK Online: An Evidence-based Website Developed to Address Adolescent Obesity
}

Tandalayo Kidd, PhD, RD, LPN

Assistant Professor and Extension Specialist

Department of Human Nutrition

Kansas State University

203 Justin Hall

Manhattan, KS 66506-1407

785-532-0154 (wk)

785-532-1678 (fax)

kidd@humec.ksu.edu

Elaine Johannes, $\mathrm{PhD}$

Assistant Professor and Extension Specialist

School of Family Studies and Human Services

Kansas State University

Larry Simonson

Project Manager

Department of Human Nutrition

Kansas State University

Denis Medeiros, PhD, RD

Head, Department of Human Nutrition

Kansas State University

\section{INTRODUCTION}

Nearly 9 million children and adolescents are overweight in the United States. The prevalence of overweight children aged 6-11 and overweight adolescents aged 12-19 has more than tripled in the past 30 years. ${ }^{1}$ Recognizing overweight and obese children may be quite easy. However, contributing factors such as family, medical, and/or dietary history and associated risk factors such as hypertension, heart disease, and diabetes make addressing the overweight/obese issue complex. ${ }^{2}$ The Institute of Medicine ${ }^{3}$ recommends multiple stakeholders from various segments of society, including families and communities, to address this growing public health problem. 
The purpose of this project was to develop an evidence-based website that provided parents, community advocates, and youth workers reliable, useful and action-oriented resources to address early adolescent (ages 11-14) obesity.

\section{WEB SITE DEVELOPMENT}

KNACK (Knowledge of Nutrition and Activity for Communities in Kansas) Online (www.knackonline.org) is a website that was developed by representatives Kansas State University, K-State Research and Extension, Kansas Department of Education, Kansas Department of Health and Environment, and other state agencies and community organizations. These representatives made up the team of stakeholders (Figure 1) who provided subject matter content, computer and web design skills, knowledge of the audiences’ needs and marketing. Focus groups were conducted with the representatives to determine specific target audiences, appropriate content needed, and organization of the website. As a result of the focus groups, the KNACK Online website contains four major sections based on the different roles an adult may

play in an adolescent’s life: 1) Parent, 2) Adult Youth Worker, 3) Community Advocates, and 4) Personal Choice (Figure 2). Kansas State University faculty with content expertise in these areas was engaged in writing parts of the site. This project was approved by the Institutional Review Board for Human Subjects via expedited review.

The Parents section is written for adult family members who care for adolescents. This section provides information on getting involved with community-related events that impacts adolescents' health, assisting adolescents with making healthier choices, and getting involved with their adolescent's school. The Adult Youth Worker section provides information for adults who work with adolescents outside of the school or home environment such as camp leaders, 
youth ministers, 4-H leaders, or after-school programs. Information on evidence-based programs such as $\mathrm{CATCH}^{\odot}$ (Coordinated Approach to Child Health), Planet Health ${ }^{\odot}$, or GO GIRLS! ${ }^{\oplus}$ is provided to assist the adult youth worker with tips and ideas for providing adolescents in their local community with nutritious foods and physical activities. The Community Advocates section provides information for adults who have formal or non-formal leader roles in their communities. Strategies for making change, communicating with federal, state, city, or county elected officials, and forming coalitions are just a few of the topics found within this section. The Personal Choice section was added specifically for adults who used the website so that they could have information to help themselves set examples and model the desired behavior for their youth.

KNACK Online provides additional resources, as identified by stakeholders that are appropriate for all levels of potential users. For example, parents with limited nutrition knowledge may benefit from tips that encourage youth involvement with the planning, purchasing, and preparation of a meal. However, an Extension worker may be interested in criteria that will help them identify evidence-based programs; whereas a researcher may be interested in some of the health promotion models such as the Health Belief Model or Transtheoretical Model (Stages of Change). The website also provides information on the latest health findings and editorials or opinion pieces written by health and nutrition researchers and educators.

\section{EVALUATION}

KNACK Online was evaluated for website organization, ease of use, value of information, uniqueness, linked resources, graphics, visual attractiveness, depth of information, and overall 
satisfaction. Approximately 20 stakeholders from the various agency/organization representatives evaluated the different sections as they were developed and added to the website. Developing an action-oriented website was the most common theme that emerged from the stakeholders’ evaluations.

After all sections had been evaluated by the representatives (stakeholders), a convenient sample of potential users such as Extension workers, school teachers, parents, health providers, and college-aged students were recruited from a K-State Research and Extension annual conference and 3 junior-level college nutrition classes. Seventy-one respondents completed the on-line survey instrument using a 5-point scale of Very Poor, Poor, Satisfactory, Good, and Very Good. Eighty-five percent (n=61) thought website organization was Good or Very Good; 83\% $(n=59)$ believed the ease of use was Good or Very Good; nearly $85 \%(n=60)$ valued the information as Good or Very Good; 70\% $(n=50)$ indicated the uniqueness of the site was Good or Very Good; 80\% (n=57) thought the linked resources were Good or Very Good; 65\% (n=46) viewed the graphics as Good or Very Good; 76\%(n=54) considered visual attractiveness as Good or Very Good; 79\% ( $n=65)$ considered the depth of information to be Good or Very Good; and $87 \%(n=62)$ rated overall satisfaction as Good or Very Good.

\section{FUTURE PLANS}

A question and answer section is provided for those who wish to ask a questions and an expert will provide the answer on the website. We plan to continue to pilot KNACK Online and continue to use it as an intervention tool in a designated community in Kansas. The KNACK Online model can also be used and adapted by other states. 


\section{ACKNOWLEDGEMENTS}

This project was funded in part by the Centers for Disease Control and Prevention grant H75/CCH724642-01

\section{REFERENCES}

1. National Center for Health Statistics. Prevalence of overweight among children and adolescents: United States, 1999-2002. Available at: http://www.cdc.gov/nchs/products/pubs/pubd/hestats/overwght99.htm. Accessed September 1, 2005.

2. American Academy of Child and Adolescent Psychiatry. Obesity in children and teens. Available at: http://www.aacap.org/page.ww?name=Obesity+In+Children+And+Teens Accessed December 15, 2006.

3. Institute of Medicine. Focus on childhood obesity. Available at: http://www.iom.edu/?id=22704. Accessed December 15, 2006. 